\title{
Mapping the hyperlinks and networks of Central and South American capital cities in three languages: consistencies and variations
}

\author{
Stanley D. Brunn • Oscar Gerardo Hernández-Lara
}

Accepted: 8 October 2021 / Published online: 2 November 2021

(C) The Author(s), under exclusive licence to Springer Nature B.V. 2021

\begin{abstract}
In a globalized, urbanized and knowledge/ information world, mapping information about places is critical for a city's local, regional, and international standing. Those networks are important in a city's positioning within a country and in a larger regional and global context. We investigate these linkages and networks by exploring the regional networks of 8 Central and 13 South American capital cities plus São Paulo and Rio de Janeiro. Our research adds a new dimension to urban places by exploring variations in the hyperlink volumes and networks in English as well as Spanish and Portuguese. Sizable language differences but also regularities were evident in the
\end{abstract}

By concentrating on the attributes of world cities and neglecting their relations, we learn a lot about the nodes in the network, but relatively little about the network itself. (Beaverstock et al., 2000a, b, p. 124)

Overlaying the centrifugal processes in each country was the increasing primacy of the urban system in most of Latin America. (Roberts, 2005, p. 110)

S. D. Brunn $(\bowtie)$

Department of Geography, University of Kentucky,

Lexington, KY, USA

e-mail: brunn@uky.edu

O. G. Hernández-Lara

Facultad de Ciencias Sociales y Políticas, Universidad

Autonoma de Baja California, Mexicali,

Baja California, Mexico

e-mail: oscar.hl2727@gmail.com hyperlink volumes of individual cities and in hyperlink pairs. The maps illustrate regional variations and unevenness in the knowledge about places and their networking in a Latin American context.

Keywords Knowledge/information economics . Urban linkages · Places · Cores and peripheries . Language variations

\section{Introduction}

The emergence of post-industrial economies, societies, and politics has ushered in new topics for the social and policy sciences (Castells \& Hall, 1994; Santos, 1996; Castells, 2000, 2005; Zook \& Brunn, 2006; Glaser \& Marshall, 2016). One of the salient features of these worlds relates to knowledge production, that is, the amount or volume of information produced or known about a specific place. The information when analyzed, mapped and graphed help us understand the nature and extent of linkages and the place of a city in a broad national or regional hierarchy. Geographers are among the scholars looking at these features whether related to information production or the increased importance of visualizing place knowledge and networks operating at local, regional, and global scales (Garreau, 1991; Dahlman \& Anderson, 2000; Stirbu et al., 2015; Hiernaux \& Lindón, 2017; Alvarez, 2019a, 2019b). These 
inquiries are signature features of knowledge/information worlds. Evidence of these scholarly worlds is illustrated by growing disciplinary and transdisciplinary literatures with a strong place-knowledgeinformation context. These include financial services, advertising, recreation and tourism, health, education, consulting, media clusters and the role that place and space play in national and transnational planning and policy. The major objective of this research is to discuss and analyze variations in the links and networks in three different languages in a set of cities in a region.

\section{Conceptual framework}

As noted in the literature cited above, when discussing the importance of cities in a region some standard norms are used to measure the importance of an individual city and the connections between cities. One parameter is population size, with a larger city considered more important than a smaller one. Geographers have used the term primate or primary city to refer to the largest city. And when geographers examine cities in a country's urban hierarchy, the capital city is often considered most important, especially if it is also the largest. It is not only important as a seat of national government but is often the leader in production of goods, hence the urban-industrial label. These largest cities also have a high ranking based on their leadership role in a combination of services such as trade, transportation, health, education, finance, real estate, tourism, law and government as well as political and economic influences, all of which were noted by Saskia Sassen (1991, 1994) and her work regarding global cities. In a contemporary light, these services, or a combination, are more important than the production of iron and steel, motor vehicles, construction equipment, farm machinery or military hardware. Mixes of information services form the economic backbone of most capital cities today.

Scholars studying the urban hierarchies and connections of cities within a broad or expansive region may discover that the largest and most important city is not the capital city. The most important city is a place attracting migrants or luring foreign investment or hosting a cluster of government or private services; it may not be the nation's capital. In a Central and South American context, the most cited example is
Brasilia, which is Brazil's national capital. Brasilia is not the country's largest or most important economic city; these would be either São Paulo or Rio de Janeiro, or both. In a world context we can also think of Canberra, Washington, DC, Pretoria, Ottawa, and New Delhi, all which are national capitals, but not the major economic or cultural hub in their country. Sydney, New York, Cape Town, Toronto, and Mumbai are larger and would have the most linkages with other cities in their country. In this study, São Paulo and Rio Janeiro are used when discussing Brazil.

Aside from population size and gross domestic product being important in a city's ranking within its country and region, linkages or connections with other cities need to be highlighted. These linkages in a traditional context would be highway and rail transportation connections; today they would also include airline connections. How intensive or extensive these linkages are in number and density defines many a primary city today. Migration from nearby rural areas or small towns and cities have stimulated the country's growing economy and solidified its top place in a national or regional context. Growth also may come from foreign investments especially in the tertiary sector. The largest cities are clearly the major "winners" in this growth and expansion "game." These flows are important in building, retaining and strengthening a growing variety of human services including retailing, financial investments, health care, hospitality, fashion, sports and entertainment, higher education, recreation, and tourism, all of which are important in the production, consumption and exchange of information and communications technology (ICT) services. Sorting out the number of firms and work force size would reveal the increased importance of information/knowledge production.

Salient questions for geographers and urban planners interested in analyzing and measuring these corporate, personal and professional services in places, such as capital cities, are how to identify and measure them and how to illustrate what is happening beyond an individual city and in a regional context. Data collected by governments, nongovernmental organizations and many segments of the service economy can be used to show what is going on within, between and among cities at local, national, and international scales. These information volumes and linkages provide a reading on a city's place in a nation and in a region, not simply its population size, airline 
traffic, tourist flows, financial investments or high tech companies.

A challenge urban scholarly communities face in looking at the contemporary global picture of urban transactions, interactions, and linkages is identifying a database that will help us understand what is going on, where and why. Answers will help us better understand the emerging postindustrial knowledge economies not only in primary cities, but in secondary and tertiary cities within individual countries but also around the world.

\section{Background literature}

This study builds on an interdisciplinary world city literature that has explored large cities and major cities for more than a half-century. It includes the early and later work on primate cities (Jefferson, 1939; Martin, 1961; Linsky, 1965; Mayer, 2019), world cities (Hall, 1966), hierarchies (Sassen, 1991, 1994, 2002, 2004, 2010, 2018; Taylor, 1997), networks and structures (Amin \& Thrift, 1992; Castells, 1996); information producer cities (Storper, 1997), connections and flows (Soja, 1989; Short et al., 1996; Kim, 1999; Short \& Kim, 1999; Mitchelson \& Wheeler, 1994; Smith \& Timberlake, 1995), and hierarchies and systems (Beaverstock et al., 1999a, 1999b, 2000a, 2000b, Boulton et al., 2011a, b; Taylor, 1997, 2004; Krãtke and Taylor, 2004; Taylor \& Deridder, 2004; Taylor et al., 2007; Taylor et al., 2015).

Among the shortcomings mentioned in the literature are detailed investigations of regional flows and linkages, a point noted by Short and Kim (1999) and Beaverstock et al. (1999a). Beaverstock et al. sought to narrow this gap by focusing on 55 world cities they included in alpha, beta and gamma levels as part of the Globalization and World Cities (GaWC) database used in multiple research projects associated with world city networks (GaWC, 2020). They defined these service-oriented cities as "advanced producer cities," that is, the number of offices related to accounting, advertising, banking/finance and commercial law. They placed these within the context of a "new metageography" that calls for attention to the patterns of flows between large urban nodes or global cities. London was used as a case study that exemplifies this label. Alpha cities are well integrated into the world economy, beta and gamma cities less so.

In a similar vein, other geographers have looked at the linkages or connections of individual cities within the context of the Google Scholar database. It has been used to gain insights into urban linkages and networks in other world regions such as Europe, Asia, and the Caribbean (see, for example, Brunn \& Dodge, 2001; Brunn, 2003; Williams \& Brunn, 2005; Brunn et al., 2010; Boulton et al., 2011a, 2011b; Devriendt, 2011; Brunn, 2019). However, Google Scholar has not been used to examine either Latin American urban networks or the volume of connections in different languages.

Google Scholar provides information that is constantly updated. The hyperlink numbers can change from day to day or even hour to hour. Because of these features, it is a valuable resource to measure the importance of information in a service-based economy. Aside from comparing the volume of hyperlinks associated with a primate city and other cities in a region, Google Scholar can be used to compare volumes of paired hyperlinks (two or more cities). Such comparisons can also be constructed for hyperlinks in different languages. Results in different languages represent one of the innovations in this research project. While English has been used previously to measure the importance of a city or pairs of cities, this study is the first to compare and analyze Google Scholar data for individual cities and networks of cities in other languages. Latin American cities are used in this study.

Google Scholar data are more useful in comparing individual cities or connections between cities than only using population data or trade in computers or companies producing software. Google Scholar measures that knowledge production in hyperlinks. Hyperlinks can be considered electronic data showing pieces of information about a city; they can be used to measure how important an individual city is within a country or region, such as Lima in Peru or Caracas in Venezuela, or how important pairs are, such as Buenos Aires, Argentina and Santiago, Chile or Managua, Nicaragua and Tegucigalpa, Honduras. We could use data collected for a number of cities in México or Brazil to identify which cities are most important and which are most linked to each other. Google Scholar focuses on scholarly literature, including journal articles, book reviews, chapters, books and reports 
about a variety of topics including demography and housing, banking and other financial services, advertising, health care, research institutions, transportation, tourism, and popular culture. It is different from Google, which includes a wider range of materials, some commercial, personal and professional.

\section{Regional setting}

It is against this backdrop on the emergence and growth of "place information worlds" that we focus on the hyperlink volumes and exchanges of capital cities in Latin America. It is a region with several very large capital cities including México City, Buenos Aires, and Santiago, but also some medium sized cities including Guatemala City, Panama City, and Asunción, and some very small capitals including Paramaribo, Cayenne and Suriname. We also includes two very large cities, São Paulo and Rio de Janeiro, which are not capitals, but play major roles in the region's economy, culture and politics.

This research builds on the valuable earlier work on Latin American cities by Griffin \& Ford, 1980; Ingram \& Carrol, 1981; Gilbert \& Ward, 1982; Roberts, 2005; and more recently by Clouser et al. (2020) and Godfrey and Hays-Mitchell (2020). Recent studies have also addressed the growing importance of the region's information economies and societies (Aguilar, 2002, 2004a, 2004b; Bacerra et al., 2013; Orduna et al., 2015; Alvarez, 2019a, 2019b; Almandoz, 2008, 2020; and Lechon \& Ramos, 2020). We address four major questions about of the region's capital cities: (1) what database can best be used to discuss urban information economies, (2) what is the volume of paired hyperlinks for each capital city to all others, (3) do the results reveal distinct "core, semiperiphery and periphery cities" in Central and South America, and (4) are there distinct variations in Google Scholar hyperlink information in English, Spanish, and Portuguese? Answers to these questions will help us understand how knowledge production economies and exchanges vary and are emerging across Latin America.

In the following sections we discuss the database and methodology and analyze the findings about individual cities and linkages with other capitals in the region. We also examine similarities and significant differences in English, Spanish, and Portuguese. The volume of hyperlinks of a given city will vary depending on national or colonial histories, variations in regional and extraregional trade in information technology products and services, language differences in the introduction and diffusion of information economies and the technologies used by individuals, economic and social institutions, governments, and nongovernmental organizations.

\section{Data source}

In thinking about the questions raised above, it is useful to briefly consider the criteria scholars have used previously to measure the amount of interaction and exchanges between and among places in a country or within a region, such as road and rail connections, air traffic volume and connections, and exports and imports. If scholars today were asked to identify the best resources to measure the importance of major cities and the volume of interactions between and among them, some scholars would identify financial transactions such as investments, consulting, regulations, international aid, or real estate. The economies of some of these major cities would focus specifically on the tourist, leisure, sports, and entertainment markets. The economies of others would be based on new universities, research laboratories, and services focusing on some cutting-edge topics about health care, green energy, sustainability or architecture. And there also would likely be entirely new economies specializing in new ICT products for the workplace and offices, consulting, translations, the print and visual media, security, international law, nongovernmental organizations, and governments. What is desired is an international database or knowledgeproduction center that gathers and periodically publishes comprehensive data on information production, consumption and trade. Unfortunately, no such standardized or extensive international database exists at a global scale. What we use is the Google Scholar search engine which has been used by others to explore placebased knowledge questions at national scales. It is an information database at its core that can be used to measure the importance of individual capital cities and the linkages between them. 


\section{Methodology}

We identified the volume and networks of Google Scholar hyperlinks for all capital cities in Central and South American countries as well as São Paulo and Rio de Janeiro. The name of each capital city and country (for example, Managua, Nicaragua) was entered as a search term and the number of hyperlinks was provided immediately. We performed this task during November 2019 for 8 Central American and 13 South American capitals plus São Paulo and Rio de Janeiro (Fig. 1). We gathered this information to create English, Spanish, and Portuguese databases.

For an analysis of "paired hyperlinks" we entered the names of two cities and countries in the search bar, for example, Quito, Ecuador + Bogotá, Colombia. We performed this task for each pair of capital cities in Central and South America plus São Paulo and Rio de Janeiro. Excel files $(23 \times 23)$ were constructed in English, Spanish and Portuguese. The individual column and row entries in the language files inform us which cities had the fewest and most hyperlinks and which had the most and fewest "pairs." As expected, there were vast differences in the paired city data. These data were used in the numerical analyses and graphics discussed in the next section.

\section{Some basic findings}

Populations of capital cities and two other Brazilian cities

The combined total population of the 23 cities was 106 million. The two largest were São Paulo and México City, with 20.9 and 20.4 million residents, respectively. Next were Buenos Aires (15.1 million), Rio de Janeiro (12.1 million), Lima (11.5 million), and Bogotá (10.7 million). These six cities had 91 million inhabitants or $86 \%$ of the total city populations in the region. At the other end of the spectrum were Cayenne with 58,000 residents and Belmopan with only 14,000 residents; their combined population was one-third that of Georgetown's population $(235,000)$.

Language variations in capital cities

Some stark differences were noted in hyperlink volumes, not unlike the population numbers mentioned above. While the hyperlink numbers were quite similar for the three languages (52.9 million for all three languages), the percentages varied from city to city (Fig. 2). The most were in Spanish (19 million or $36 \%$ ) followed by English (17.3 million or 33\%) and Portuguese (16.6 million or $31 \%$ ). The cities with the largest combined totals, not surprisingly, were Buenos Aires (5.7 million), Rio de Janeiro (5.7 million), México City (5.5 million), São Paulo (5.4 million), and Santiago (5 million). These five had 52\% of all combined hyperlinks. Rio de Janeiro and São Paulo have similar hyperlink totals. Both are important in Brazil and Latin America; Rio de Janeiro has an economy built on a strong industrial base and tourism economy whereas São Paulo's strength is in the corporate, financial and information sectors. The cities with the fewest hyperlinks were Paramaribo (180 million), Belmopan (130,000), Georgetown $(123,000)$ and Cayenne (only 97,000) for a total of 530 million or $10 \%$ of the total.

The total volume of hyperlinks for the 23 cities in English was 17.3 million, as noted above. The most were for México City with 3 million and the fewest for Belmopan, Belize with only 32,000. An additional four cities had more than 1 million hyperlinks each. They were (in order): Buenos Aires, Santiago, São Paulo, and Rio de Janeiro. These four cities plus México City had 11 million hyperlinks or $21 \%$ of the total. Brasilia's hyperlink total was 395,000, slightly larger than La Paz at 368,000 . As was the case with the combined totals mentioned in the previous paragraph, the fewest English hyperlinks were for Paramaribo, Belmopan, Georgetown and Cayenne; their combined total in English was only 52,000, about the same as for Tegucigalpa $(52,300)$ and slightly more than for Asunción (32,000).

In Spanish the total volume of hyperlinks for the 21 capital cities plus São Paulo and Rio de Janeiro was 19 million. Those with the most were Buenos Aires (2.1 million), México City (2 million) and Santiago (1.8 million); next were Guatemala City (1.4 million), San Salvador (1.4 million), Lima (1.3 million), Bogotá (1.2 million), San José (1.2 million) and Panama City (1 million). These 9 cities combined had 13 million hyperlinks or $72 \%$ of the Spanish-language total. Rio de Janeiro and São Paulo together had 1.3 million hyperlinks, less than San Salvador's total; both Brazilian cities had more hyperlinks in Spanish than Brasilia. The cities with the fewest were Paramaribo, 


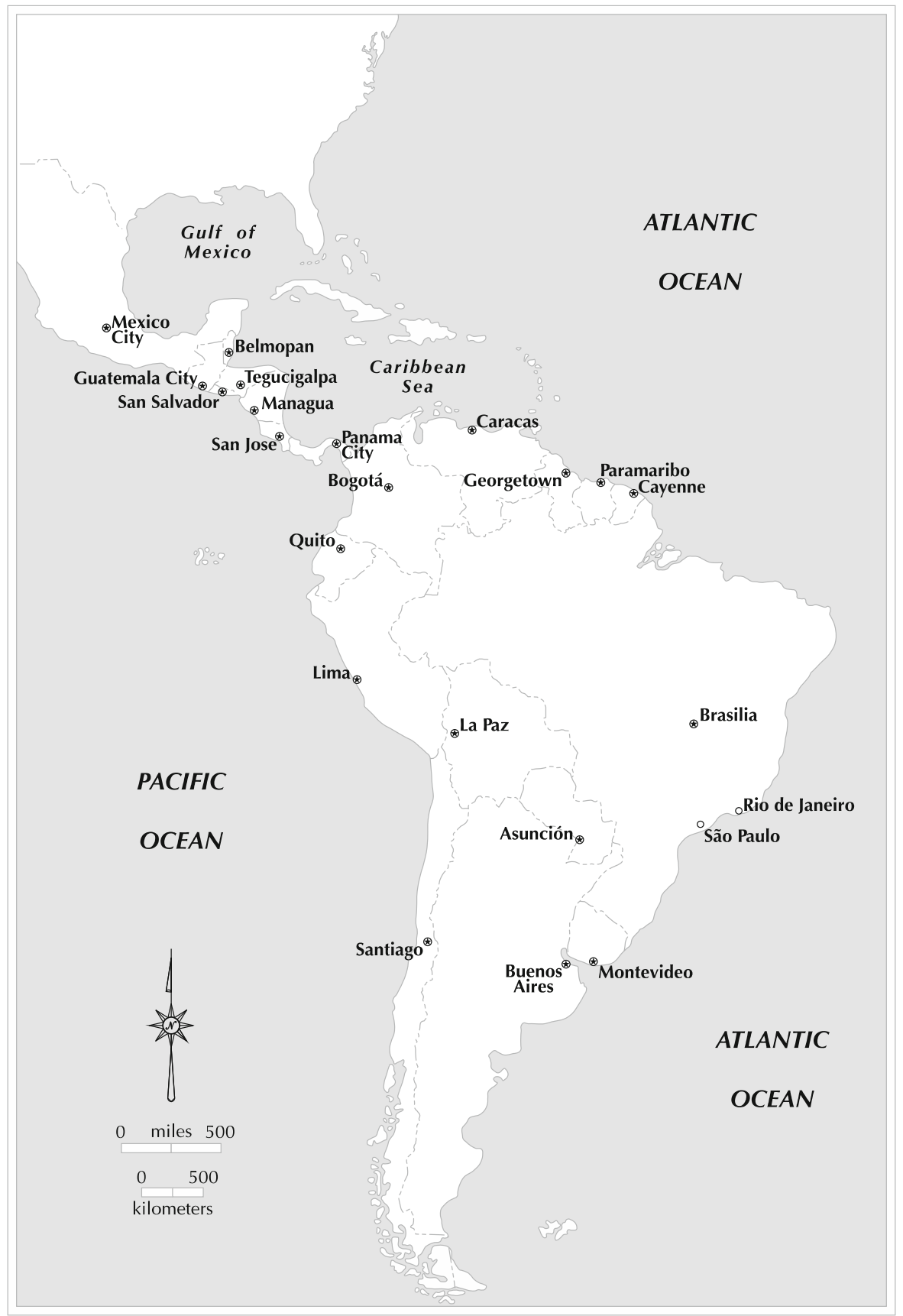

Fig. 1 Cities of Central and South America

Belmopan, Georgetown and Cayenne; their combined total was 359,000 hyperlinks which was only slightly more than Asunción's total $(304,000)$. Tegucigalpa's total was the second lowest (after Belmopan) of any Central American country; Managua was the region's lowest capital city in Spanish hyperlinks.
The results in Portuguese were much different from the Spanish and English totals in that $47 \%$ of the total were for the three Brazilian cities. This result was not surprising. There were slightly more hyperlinks for Rio de Janeiro (3 million) than for São Paulo (2.8 million). Brasilia's total (2 million) was more than any 


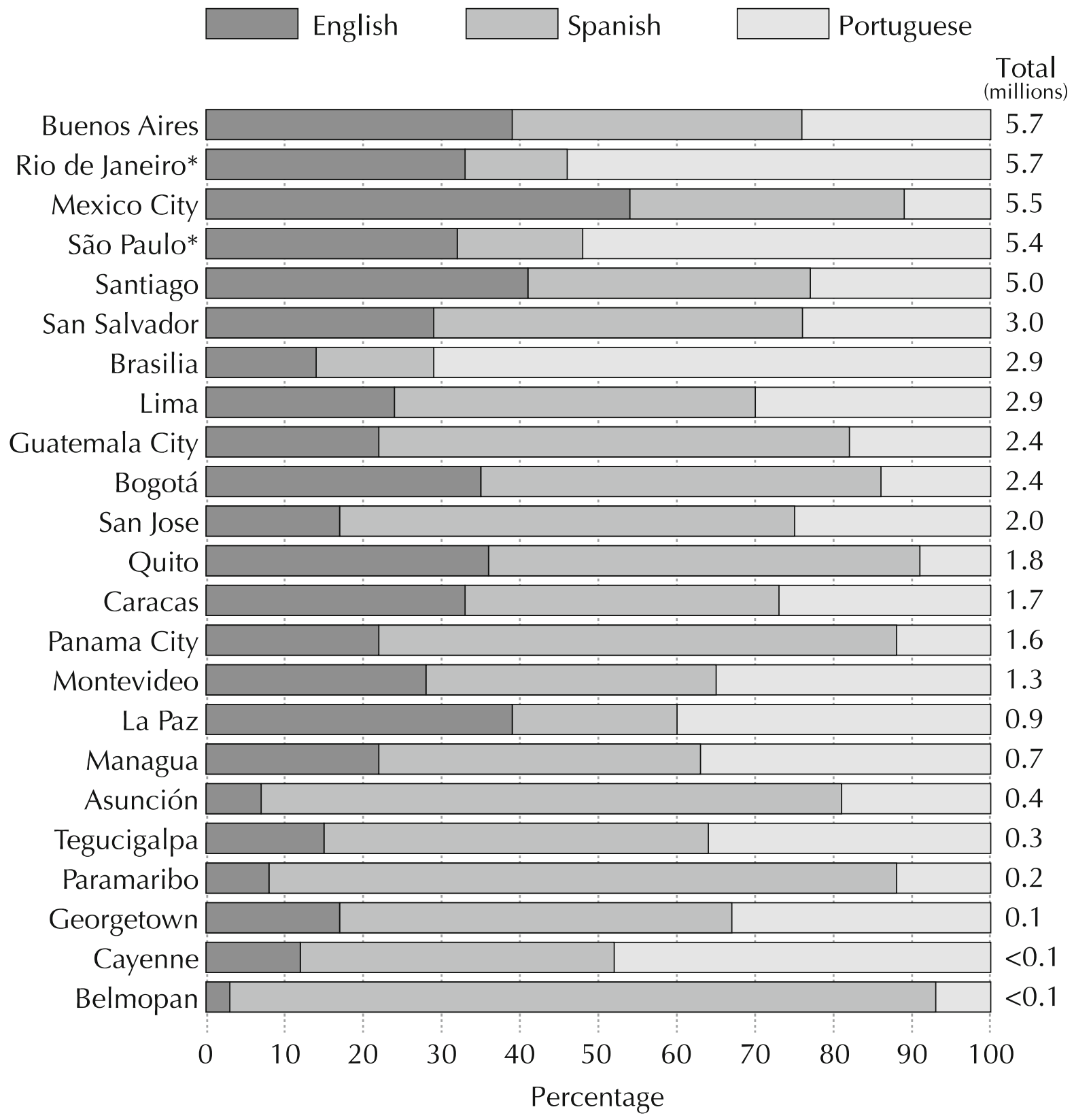

* Not capital cities, but included in this research

Fig. 2 Percentage of capital city hyperlinks in three languages ( Source: Data from Google Scholar, November 2019)

Portuguese-language capital in Central and Latin America. The Portuguese-language capitals with the most hyperlinks were Buenos Aires (1.7 million) and Santiago (1.1 million). The four cities with the fewest Portuguese hyperlinks were the same as those above which had the lowest totals in Spanish and English. They were Cayenne (45,800), Georgetown $(40,700)$,
Paramaribo (22,100), and Belmopan $(9,200)$; their combined total was slightly less than that for Tegucigalpa $(122,000)$. 
Paired hyperlink volumes with regional capitals

We next explored the total volume of hyperlinks of each Central and South American city with all others, including São Paulo and Rio de Janeiro. The total was 14.7 million hyperlinks. Our objective was to identify both the most and least linked cities. The leading city in paired hyperlinks with all cities in the study area was México City with 3 million total or about $20 \%$ of the total. The top 5 cities in paired hyperlinks, each with more than 1.7 million, were México City, Rio de Janeiro, Buenos Aires, Santiago, and São Paulo. These 5 had 12 million total hyperlinks or $81 \%$ of the total. At the other extreme were Paramaribo with 14,400 , Cayenne with 12,100 and Belmopan with only 4,400. Brasilia's total links with regional capitals were 420,000, only slightly more than La Paz and less than Guatemala City.

Linkages to other Central and South American cities in three languages

Further insight into the linkages of these cities is gained by looking at each city's "most linkages" to other capitals in the region. The linkages are shown in Figs. 3, 4, 5. There was not one dominant city linking most of the capitals; rather several distinct patterns emerged. The city linked to most others was Buenos Aires; it was most linked to five cities: Quito, Caracas, La Paz, Santiago, and Montevideo. São Paulo and México City were the second and third cities with most links to other cities in the region; each had four links to others. São Paulo was linked to Rio de Janeiro, Asunción, Paramaribo, and Cayenne, while México City was linked to Guatemala City, Panama City, Bogotá, and Georgetown. Five cities had two major links: Rio de Janeiro to São Paulo and Brasilia, Guatemala City to México City and Belmopan, San José to Tegucigalpa and San Salvador, Santiago to Buenos Aires and Lima, and San Salvador to San José and Managua.

The diversity described above for the most linked cities carried over to the second most linked cities. In fact, there were many more cities identified (12) as second leading cities than those ranking first. Lima was the leader; it was the second leading city in links with Bogotá, Quito, Caracas, and La Paz. Guatemala City was second with links to three cities: Tegucigalpa, San Salvador, and Panama City. Buenos Aires,
Belmopan, Rio de Janeiro, São Paulo, México City, and San Salvador were linked to two capitals and Panama City, Managua, and Brasilia to only one.

When we examine the linkages in English of each capital city to all others in the region, the results do not present a clear picture. Rather, there is a mix of cities being ranked, especially in the Central American region (Fig. 3). For example, México City is most linked to Central American cities (Guatemala City, San José, San Salvador, and Panama City as well as Bogotá and Georgetown which are nearby). Four cities are most linked to Buenos Aires (Caracas, Santiago, Montevideo, and $\mathrm{La} \mathrm{Paz}$ ) and four others to São Paulo (Asunción, Cayenne, Paramaribo, and Rio de Janeiro). Three Central American cities, México City, Tegucigalpa, and Belmopan are most linked to Guatemala City. Two cities, São Paulo and Brasilia, not surprisingly, are most linked to Rio de Janeiro. Lima and Buenos Aires are most linked to Santiago. Examples of cities with single links are Managua to San Salvador and Quito to Bogotá. In short, the Central American cities are closely linked with others in close proximity while those on the South American continent display more variation.

The Spanish results reveal some different patterns (Fig. 4). Buenos Aires is the leading city with linkages to 8 cities, all in South America except México City. The other cities are Lima, Asunción, Santiago, Montevideo, Rio de Janeiro, Caracas, and Brasilia. México City's major linkages are with Managua, Bogotá, and Quito. The Central American cities are linked to two capitals: Guatemala City, San José, and Paramaribo to San Salvador; Tegucigalpa, Panama City, and Cayenne to Guatemala City. Four cities are most linked with a single city: Panama City to San Salvador, São Paulo to Brasilia, La Paz to Quito, and Belmopan to Managua.

The Portuguese results are not surprising (Fig. 5). São Paulo and Rio de Janeiro have more links with other capitals than does Brasilia. Six capitals are most linked to São Paulo: La Paz, Rio de Janeiro, Montevideo, Asunción, Bogotá, and Panama City; three to Rio de Janeiro: México City, São Paulo, Brasilia; four to Buenos Aires: San Salvador, Quito, Santiago and Caracas; and three to Guatemala City: Belmopan, Tegucigalpa, and Cayenne. Single city linkages are Guatemala City to San José, Paramaribo to Georgetown, Georgetown to Montevideo, and Managua to San Salvador. 
Fig. 3 Most paired hyperlinks in English ( Source: Data collected from Google Scholar, November 2019)

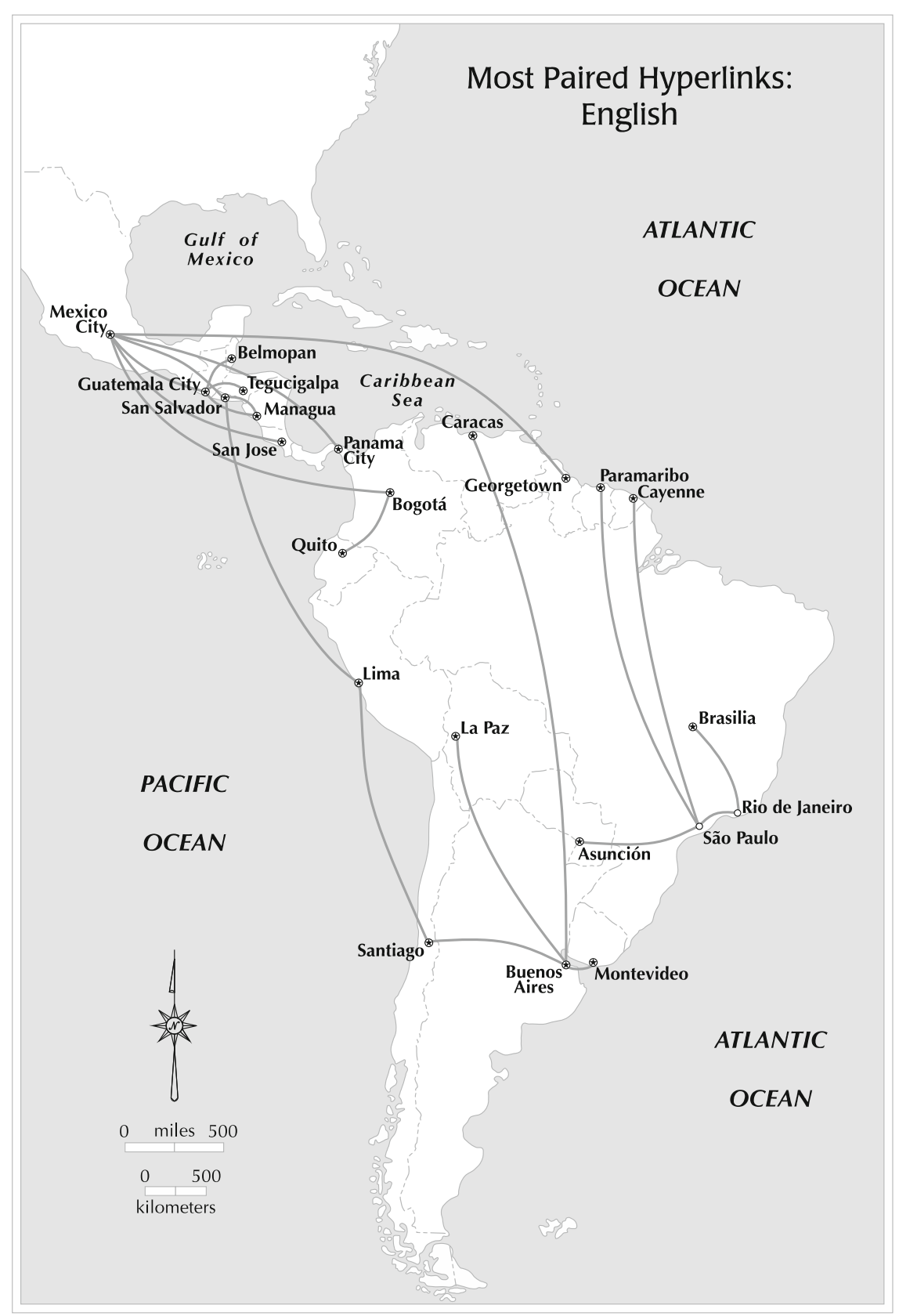

Capital cities with fewest paired linkages

As was noted above, the capital cities with the fewest paired hyperlinks consistently in all languages were Belmopan, Georgetown, Paramaribo, and Cayenne. In some cases, the fewest were for Belmopan (San José, Panama City, Asunción, and Buenos Aires), while in other cases Cayenne or Paramaribo vied for second.
Georgetown in most cases had very few, but slightly more than Cayenne, Paramaribo and Belmopan. Often these paired hyperlinks were less than 2 million and sometimes even less than 10,000 links to some capitals, especially to Belmopan. 


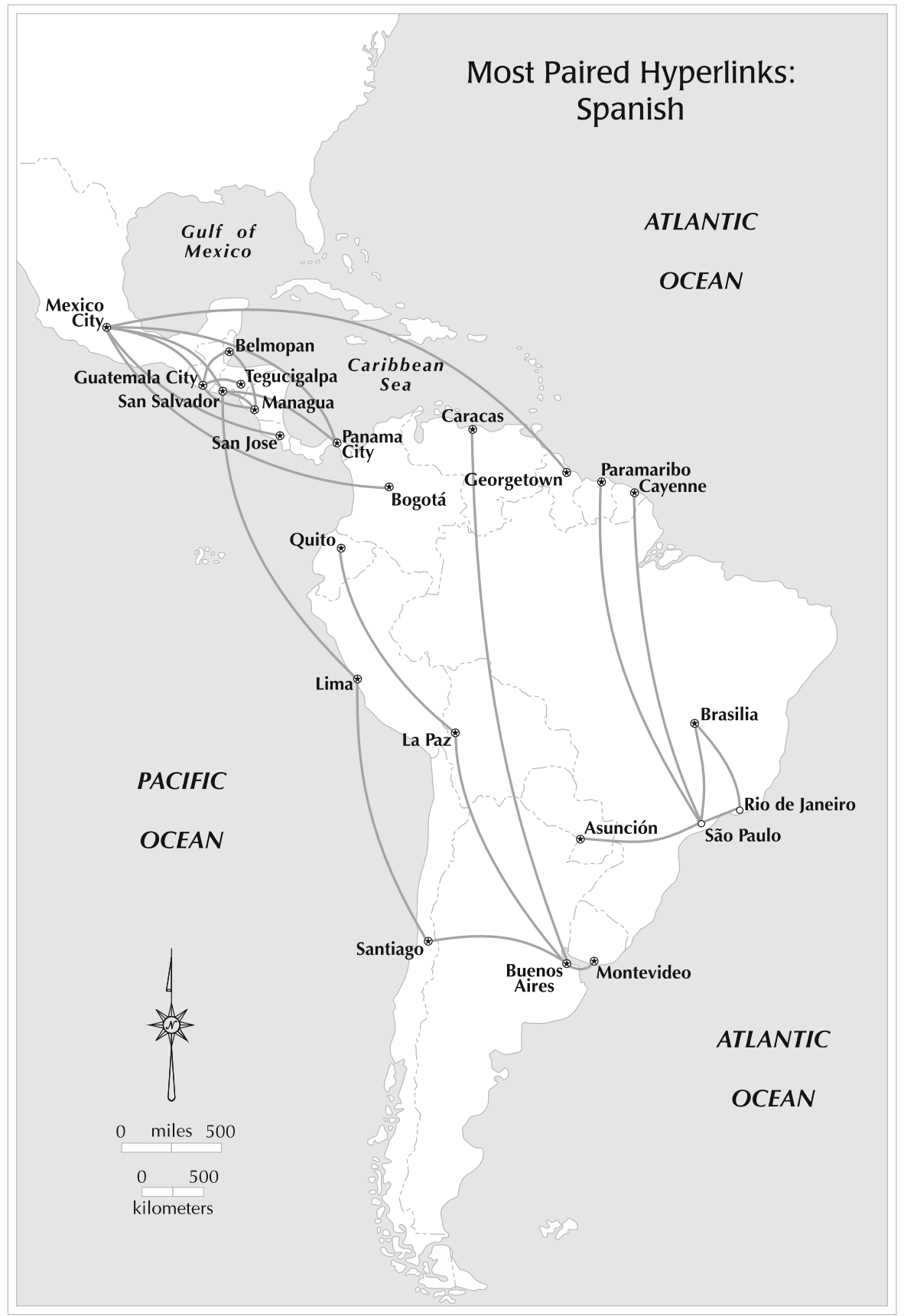

Fig. 4 Most paired hyperlinks in Spanish ( Source: Data gathered from Google Scholar, November 2019)

Cities in a core-periphery context

We obtain another perspective on the region's urban structure by placing the results in a core-periphery context (Fig. 6). This figure is based on the volume of hyperlinks in all three languages; the graphic would be similar if we used Spanish or Portuguese data. In the core are the 5 cities with more than 5 million hyperlinks each: Rio de Janeiro, México City, Buenos Aires, São Paulo, and Santiago. In the semiperiphery are cities with 1-5 million hyperlinks: Guatemala City, San José, Panama City, Bogotá, Quito, Lima, 
Fig. 5 Most paired hyperlinks in Portuguese ( Source: Data gathered from Google Scholar, November 2019)

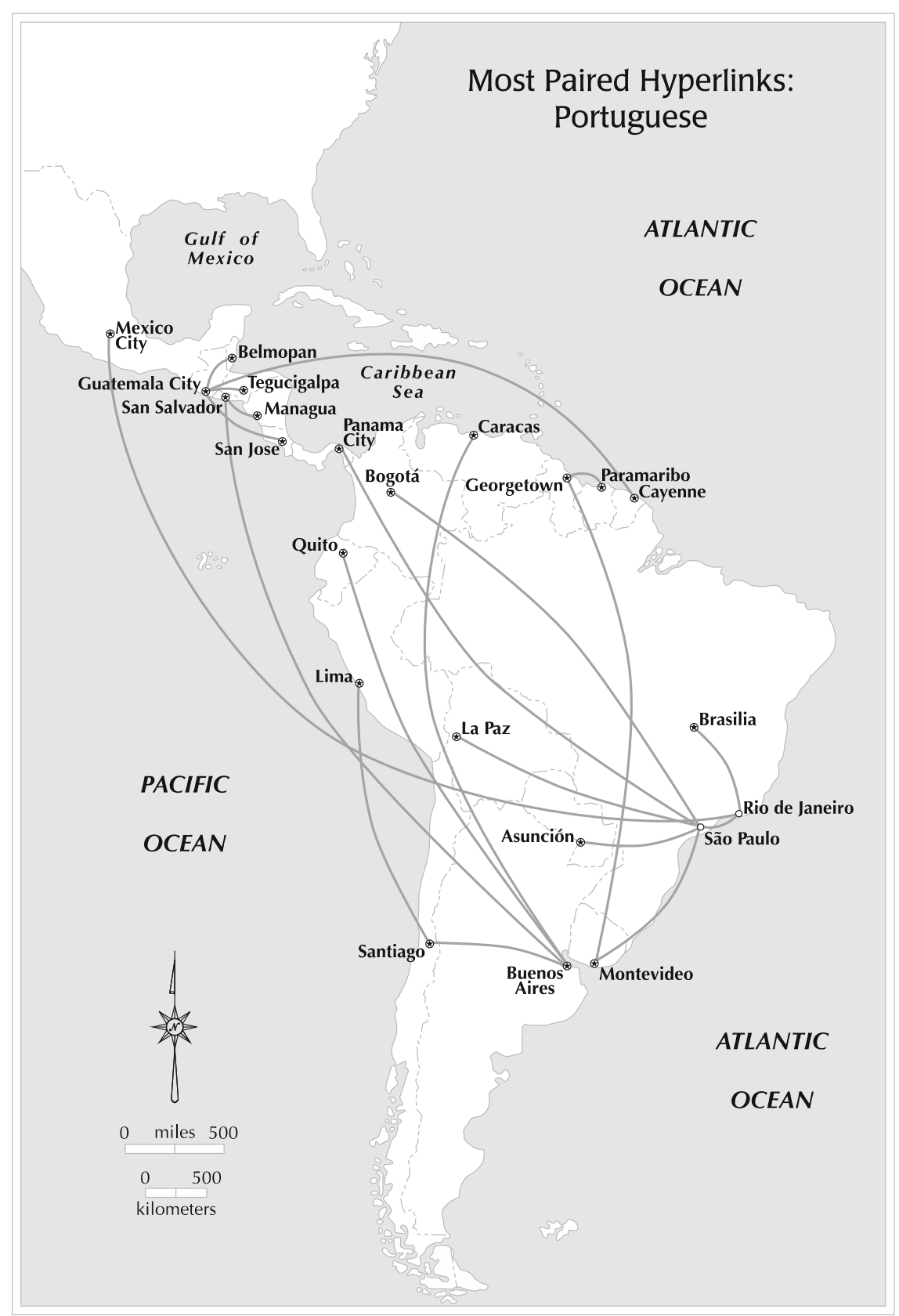

Montevideo, San Salvador, and Brasilia. The periphery includes two cities with 500,000-999,999 hyperlinks: La Paz and Managua. And in the deep periphery are cities with the fewest hyperlinks, that is, less than 500,000: Tegucigalpa, Asunción, Georgetown, Cayenne, Paramaribo, and Belmopan.

The cities included in the four categories illustrated in Fig. 6 are similar to the levels used in the 2020
GaWC categories (Global and World Cities, 2020). México City, São Paulo, Buenos Aires and Santiago are in the alpha level. San Salvador, Quito, San José, Caracas, Guatemala City, Panama City, Rio de Janeiro, Montevideo, Bogotá and Lima in the beta level, and Managua, La Paz, Tegucigalpa, and Asunción in the gamma level. Brasilia is in the selfsufficiency category. The GaWC dataset does not list 


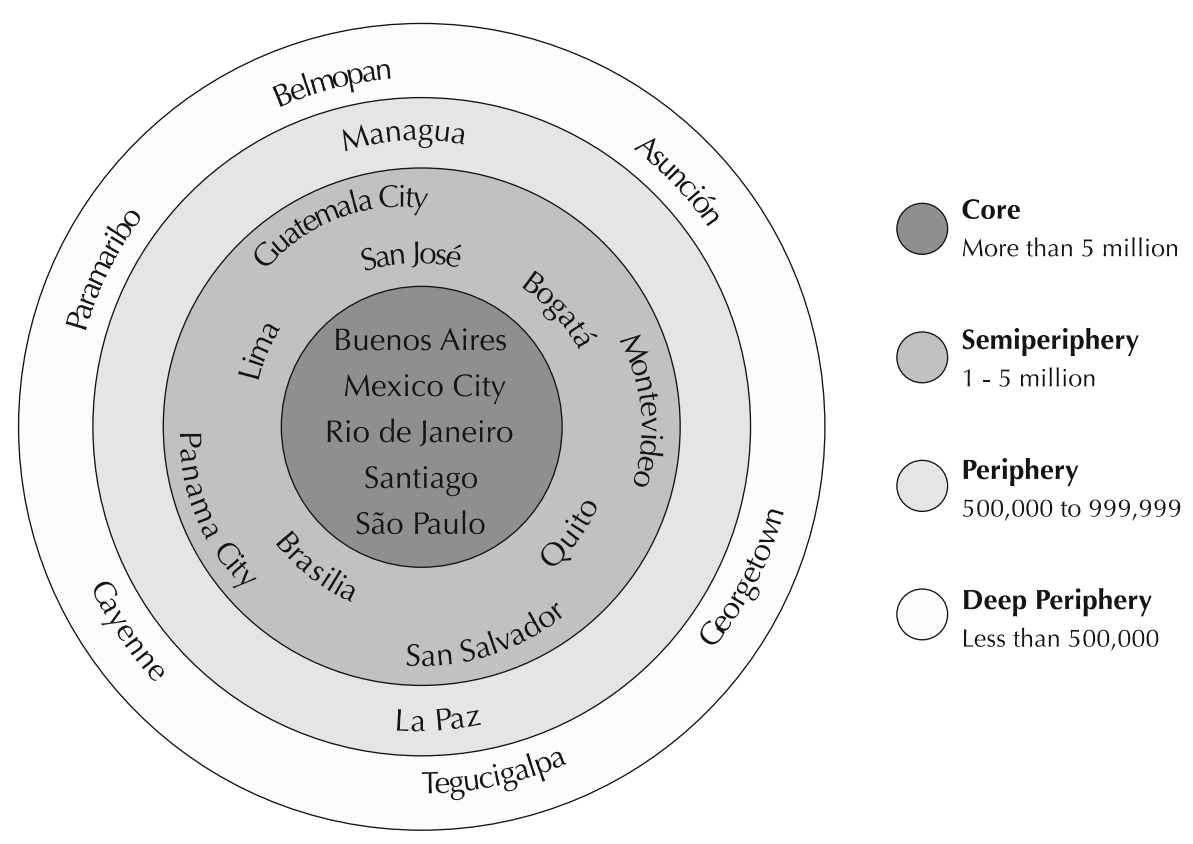

Fig. 6 Core-periphery cities in Central and South America combined hyperlinks in Spanish, English, and Portuguese

the four small cities in Latin America: Belmopan, Georgetown, Paramaribo and Cayenne.

\section{Summary and conclusions}

Examining and assessing the regional linkages of capital cities in Central and South America has yielded some expected and some unexpected results. The major findings are:

1. Looking at language variations in Google Scholar for all 23 cities discussed, the capital city with the most hyperlinks in English was México City. This result was not surprising considering its proximity to the English-speaking world. The city was the leader not only in total hyperlinks for each individual capital city in the region, but also compared to São Paulo and Rio de Janeiro. The Spanish language results were slightly different, with Buenos Aires first followed by México City and then Santiago. In Portuguese the most links, as expected, were for cities in Brazil: Rio de Janeiro was first, São Paulo second, and Brasilia third.

2. The paired linkages of Central American cities show a mix of linkages, not primarily to only one or two dominant cities in the region. This pattern was the opposite for South American capitals, where São Paulo and Rio de Janeiro were dominant as were both Buenos Aires and Santiago, which had the most links. The second ranked cities in paired hyperlinks were far fewer to these dominant cities; Lima was also a leader. The paired hyperlinks in Spanish were a slightly different order with Santiago being first followed by São Paulo and then México City. The Portuguese links were mostly to cities on the South American continent not in Central America.

3. A closer examination of the paired hyperlinks reveals a regional pattern which displays much variation hence the word "dystopia" mentioned above. The capital cities in reality belong to two different systems. Most Central American capitals have more linkages to other Central American capitals than to South American capitals, except for large numbers of hyperlinks with Rio de Janeiro, São Paulo, and Buenos Aires. The reverse is also true, that is, the South American capitals have more many links to other capitals on the continent than in Central America, except for México City, São Paulo, and Rio de Janeiro. Again, there are almost two distinct urban systems. 
4. The cities with fewest hyperlinks and fewest paired hyperlinks were, not unexpectedly, Georgetown, Paramaribo, Cayenne and Belmopan. In short, there was not only little information about each in the Google Scholar database, but they were not linked in large volumes to other large and even medium sized cities in the region. Another example of the dystopia.

5. The results identify current changes regarding the hierarchy of cities in the region. However, at the same time, they confirm the place of enormous hierarchy of global cities, as is the case of México City, Rio de Janeiro and Sao Paulo being at the top (see Figs. 2 and 6).

6. Language is also essential in considering cities in a global hierarchy. This study reveals that regardless of language, the major cities retain similar rankings.

This investigation suggests a number of additional investigations for Latin American scholars interested in urban and interurban connections vis-à-vis knowledge-based economies. We suggest four topics. One is to examine the secondary and tertiary hyperlink volumes within each country to observe if there are any differences between the capital cities and cities ranked second or third in population. For example, what percentage of all hyperlinks are in the first, second, and third ranked cities in population? Are the lion's share in the capital city or is there some evenness in the percentages? A second theme would be to examine the most important or highest ranked topics in specific subject categories identified by Google Scholar for an individual city and for pairs of cities. Google Scholar uses an in-house calculation to rank entries, not one based solely on journal ranking or the volume of citations. That is, the first five entries are more important than the second five or the next ten. One might focus, for example, on the top ten. Are they about financial services, tourism, economic development, transportation, political conflict, the COVID-19 virus, ICT innovations, environmental issues, or some area of human welfare? All are topics about specific emerging service economies? A third topic could use Google hyperlinks to explore differences in the categories of entries for various economic and social topics between Rio de Janeiro and São Paulo, specifically their regional and global networks. A fourth topic would explore in greater depth the hyperlink results in different languages, especially if there are significant differences in the volume for an individual city or a pair of cities. What are the most frequent topics for paired cities in English, Spanish and Portuguese? Are they about financial services, tourism, transportation links or cultural programs? Such inquiries would aid in our understanding of using Google Scholar to monitor ongoing research related to Latin American urban linkages, structures, development, and regional policies.

Author contributions SDB conceived the study. OG compiled the data. SDB and OG analyzed the data and wrote the manuscript.

Funding No funding was received.

Data availability All data and material are included in the manuscript.

\section{Declarations}

Conflict of interest The authors have no conflicts of interest.

\section{References}

Aguilar, A. (2002). Las mega-ciudades y las periferias expandidas. Ampliando el concepto en Ciudad de México. EURE, 38(85), 121-149.

Aguilar, A. (2004a). Procesos metropolitanos y grandes ciudades. Dinámicas recientes en México y otros países. México: H. Cámara de Diputados, LIX Legislatura; UNAM; CONACyT; Porrúa.

Aguilar, A. (2004b). Las grandes aglomeraciones y su periferia regional. Experiencias en Latinoamérica y España. México: H. Cámara de Diputados, LIX Legislatura; UNAM; CONACyT; Porrúa.

Almandoz, A. (2008). Para una reseña bibliográfica de la globalización urbana. Bifurcaciones, 7(7), 1-10.

Almandoz, A. (2020). Reconsideraciones epistemológicas y conceptuales sobre el urbanismo. EURE, 46(137), 273-284.

Alvarez, L. (2019a). Property regimes and the commodification of geographic information: An examination of Google Street View. Big Data and Society, 3(2), 1-13.

Alvarez, L. (2019b). How cars became mobile spatial media: A geographical political economy of on-board navigation. Mobile Media and Communication, 7(3), 362-379.

Amin, A., \& Thrift, N. (1992), Neo-Marshallian nodes in global networks. International Journal of Urban and Regional Research, 16(4), 571-587. https://doi.org/10.1111/j.14682427.1992.tb00197.x

Baccera, J. M., et al. (2013). Transport and health: A look at three Latin American cities. Cadermos De Saúde Pública. https://doi.org/10.1590/S0102-311X201300080004 
Beaverstock, J. V., Smith, R. G., \& Taylor, P. J. (1999a). A roster of world cities. Cities, 16(6), 445-458.

Beaverstock, J. V., Smith, R. G., \& Taylor, P. J. (1999b). The long arm of the law: London's law firms in a globalizing world-economy. Environment and Planning A, 31(10), 187-192.

Beaverstock, J. V., Smith, R. G., \& Taylor, P. J. (2000a). World city network: A new metageography. Annals of the Association of American Geographers, 90(1), 123-134.

Beaverstock, J. V., Smith, R. G., Taylor, P. J., Walker, D. R. F., \& Lorimer, H. (2000b). Globalization and world cities: Some measure methodologies. Applied Geography, 20(1), $43-63$.

Boulton, A., Devriendt, L., Brunn, S. D., Derudder, B., \& Witlox, F., et al. (2011a). City networks in cyberspace and time: Using Google hyperlinks to measure global economic and environmental crises. In R. Firmino (Ed.), Mobile and Ubiquitous Urban Infrastructure Surveillance, Locative Media and Global Networks (pp. 67-87). IGI Global.

Boulton, A., Brunn, S. D., \& Devriendt, L. (2011b). Cyberinfrastructures and Smart World Cities: physical, human and soft infrastructures. In P. Taylor, B. Derudder, M. Heyler, \& F. Witlox (Eds.), International Handbook of Globalization and World Cities (pp. 198-205). Edgar Elgar.

Brunn, S. D. (2003). A note on the hyperlinks of major Eurasian cities. Eurasian Geography and Economics, 44(4), 321-324.

Brunn, S. D. (2019). Regional and extraregional hyperlinks of Caribbean capital cities: A mosaic of multiple and fragmented cores and peripheries. Caribbean Geographer, 23(1), 1-19.

Brunn, S. D., \& Dodge, M. (2001). Mapping the "worlds" of the World Wide Web: (Re)Structuring global commerce through hyperlinks. The American Behavioral Scientist, 44(10), 1717-1739.

Brunn, S. D., Devriendt, L., Boulton, A., Derudder, B., \& Witlox, F. (2010). Networks of European Cities in Worlds of Global Economic and Environmental Change. Fennia, 188(1), 37-49.

Castells, M. (1996). The Rise of the Network Society. Blackwell.

Castells, M. (2000). Grass rooting the Space of Flows. In J. O. Wheeler, Y. Aoyama, \& B. Warf (Eds.), Cities in the Telecommunications Age: The Fracturing of Geographies (pp. 294-302). Routledge.

Castells, M. (2005). Space of flows, space of places: Materials for a theory of urbanism in the information age. In S. Bishwapriya (Ed.), Comparative Planning Studies (pp. 219-240). Routledge.

Castells, M., \& Hall, P. (1994). Tecnópolis del mundo. La formación de los complejos industriales del siglo XXI. Alianza Editorial.

Clousre, R., Mendez-Lemus, Y., \& Finn, J. C. (2020). Cities of Middle America. In S. D. Brunn, D. J. Zeigler, M. HaysMitchell, \& J. K. Graybill (Eds.), Cities of the World: Regional Patterns and Urban Environments (pp. 97-137). Rowman and Littlefield.

Dahlman, C., \& Anderson, T. (2000). Korea and the Knowledge-Based Economy: Making the Korea and the Transition. IBRD. World Bank.
De Rudder, B., \& Taylor, P. J. (2005). The cliquishness of world cities. Global Networks, 5(1), 71-91.

Devriendt, L., Boulton, A., Brunn, S. D., Derudder, B., \& Witlox, F. (2011). Search (for) cyberspace: The position of major cities in the information age. Journal of Urban Technology, 18(1), 73-92.

GaWC (Globalization and World Cities Network). (2020). Global Network. lboro.ac.uk/gawc/ Retrieved Feb 2021.

Garreau, J. (1991). Edge City: Life on the New Frontier. Doubleday.

Gilbert, A. G., \& Ward, P. M. (1982). Residential Movement among the Poor: The constraints on housing choice in latin American cities. Transactions of the Institute of British Geographers, 7(2), 129-149. https://doi.org/10.2307/ 622218

Glaeser, E., \& Marshall, A. (2016). Cities, Information, and Economic Growth. In Proceedings of the Regional Growth and Community Development Conference, pp. 9-47.

Godfrey, B. J., Hays-Mitchell, M., \& Whitson, R. (2020). Cities of South America. In S. D. Brunn, D. J. Zeigler, M. HaysMitchell, \& J. Graybill (Eds.), Cities of the World: Regional Patterns and Urban Environments (pp. 139-186). Rowman and Littlefield.

Griffin, E., \& Ford, L. (1980). A model of Latin American urban structure. Geographical Review, 70(4), 397-422.

Hall, P. (1966). The World Cities. Heinemann.

Hiernaux, D., \& Lindón, A. (Eds.). (2017). Tratado de geografía humana. Anthropos Editorial.

Ingram, G. K., \& Carroll, G. (1981). The spatial structure of Latin American cities. Journal of Urban Economics, 9(2), 257-273.

Jefferson, M. (1939). The law of the primate city. Geographical Review, 29(2), 226-232.

Krätke, S. S., \& Taylor, P. J. (2004). A world geography of global media cities. European Planning Studies, 12(4), 459-472.

Lechon, D., \& Ramos, D. (2020). Es internet un territorio? Una aproximación a partir de la investigación del hacktivismo en México. Economía, Sociedad y Territorio, 20(62), 273-301.

Linsky, A. S. (1965). Some generalizations concerning primate cities. Annals of the Association of American Geographers, 55(3), 506-510.

Martin, G. J. (1961). The law of primate cities Revisited. Journal of Geography, 60(4), 165-172.

Meyer, W. B. (2019). Urban primacy before Mark Jefferson. Geographical Review, 109(1), 131-145.

Mitchelson, R. L., \& Wheeler, J. O. (1994). The flow of information in a global economy: The role of the American urban system in 1990. Annals of the Association of American Geographers, 84(1), 87-101.

Orduna, E., Ayllon, J., Martin, A., \& Lopez, E. (2015). Methods for estimating the size of Google Scholar. Scientometrics, 104(3), 931-949.

Roberts, B. P. (2005). Globalization and Latin American cities. International Journal of Urban and Regional Research, 291(23), 110-1123.

Santos, M. (1996). A Natureza do Espaço. Técnica e Tempo, Razão e Emoção. Hucitec.

Sassen, S. (1991). The Global City. Princeton University Press. 
Sassen, S. (1994). The global city: Elements for a reading of Paris. Le Bet, 80(3), 137-153.

Sassen, S. (Ed.). (2002). Global Networks, Linked Cities. Routledge.

Sassen, S. (2004). The global city: Introducing a concept. Brown Journal of World Affairs, 11(2), 150-163.

Sassen, S. (2010). Global inter-city networks and commodity chains: Any intersections? Global Networks, 10(1), 150-163.

Sassen, S. (2018). Cities in a World Economy. Sage.

Short, J. R., \& Kim, Y. J. (1999). Globalization and the City. Longman.

Short, J. R., Kim, Y., Kuss, M., \& Wells, H. (1996). The dirty little secret of world cities research. International Journal of Urban and Regional Research, 20(4), 697-717.

Smith, D. A., \& Timberlake, M. (1995). Cities in global matrices: toward mapping the world system's city system. In T. Knox (Eds.), World Cities in a World-System (pp. 79-97). Cambridge University Press.

Soja, E. (1989). Postmodern Geography: The Resurrection of Space in Critical Social Theory. Verso.

Storper, M. (1997). The Regional World. Oxford University Press.

Ştirbu, S., Thirion, P., Schmitz, S., Haesbroeck, G., \& Greco, N. (2015). The utility of Google Scholar when searching geographical literature: Comparison with three commercial bibliographic databases. The Journal of Academic Librarianship, 41(3), 322-329.

Taylor, P. J. (1997). Hierarchical tendencies amongst world cities.: A global research proposal. Cities, 14(6), 323-332.

Taylor, P. J. (2004). World-City Network; A Global Analysis. Routledge.

Taylor, P. J., \& Derudder, B. (2004). World City Networks: A Global Urban Analysis. Routledge.

Taylor, P. J., Derudder, B., Saey, P., \& Witlox, F. (Eds.). (2007). Cities in Globalization: Practice, Policies and Theories. Routledge.

Taylor, P. J., Derudder, B., Falconbridge, J., Hoyler, M., \& Ni, P. (2015). Advanced producer services in firms as strategic networks, global cities and strategic places. Economic Geography, 90(5), 267-291.

Williams, J. F., \& Brunn, S. D. (2005). Cybercities in Asia: Measuring globalization using hyperlinks. Asian Geographer, 23(1-2), 121-147.

Zook, M., \& Brunn, S. D. (2006). From podes to antipodes: Positionalities and global airline geographies. Annals of the Association of American Geographers, 96(3), 471-480.

Publisher's Note Springer Nature remains neutral with regard to jurisdictional claims in published maps and institutional affiliations. 